\title{
Etanercept-induced pleuropericardial lupus-like syndrome
}

\section{To the Editors:}

Tumour necrosis factor (TNF)- $\alpha$ is currently being targeted in autoimmune joint diseases, including rheumatoid arthritis (RA) and spondylarthropathies [1, 2]. Widespread use of antiTNF- $\alpha$ therapies (e.g. etanercept) has unveiled a spectrum of adverse effects, including infection [3] and a systemic lupus erythematosus (SLE)-like syndrome [4]. The latter appears to be biologically based on perturbations in TNF- $\alpha$-controlled homeostasis of interferon (IFN)- $\alpha$ [5], and is betrayed by seroconversion of SLE markers [6]. With interest, we read the occurrence of pleural effusions associated with anti-TNF- $\alpha$ agents [7]. We encountered a patient with RA taking etanercept, who developed alternating pleural effusions. We obtained measurements that suggested that a lupus-like syndrome and not a common drug reaction precipitated these pleural effusions.

A 50-yr-old Greek ex-smoker presented with acute-onset fever $\left(39^{\circ} \mathrm{C}\right)$, malaise and right-sided pleuritic pain. She had longstanding seropositive RA and was started on $25 \mathrm{mg}$ bi-weekly subcutaneous etanercept 3 yrs earlier (when tuberculin skin test was $0 \mathrm{~mm}$ and chest radiograph negative). Her prior serology was: negative antinuclear antibody (ANA) and antidouble stranded (ds)DNA antibody and a rheumatoid factor $(\mathrm{RF})$ of $35 \mathrm{U} \cdot \mathrm{L}^{-1}$. On admission, a free-floating right-sided pleural effusion (fig. $1 \mathrm{a}, \mathrm{b}$ and c), haemolytic anaemia (haematocrit $30 \%$, positive indirect Coombs' test), leukocytopaenia $\left(4,000\right.$ cells $\left.\cdot \mathrm{mm}^{-3}\right)$ and microscopic haematuria (100 red cells $\cdot \mathrm{mm}^{-3}$, no casts) were found. Serum RF and ANA were $65 \mathrm{U} \cdot \mathrm{L}^{-1}$ and 1:640, respectively; a tuberculin skin test was $12 \mathrm{~mm}$, while thoracentesis yielded an exudate ( $\mathrm{pH} \mathrm{7.22;}$ glucose $68 \mathrm{mg} \cdot \mathrm{dL}^{-1}$, lactate dehydrogenase $(\mathrm{LDH}) 704 \mathrm{U} \cdot \mathrm{L}^{-1}$, protein $4.6 \mathrm{~g} \cdot \mathrm{dL}^{-1}, 6400$ nucleated cells $\cdot \mathrm{mm}^{-3}, 80 \%$ neutrophils, $10 \%$ lymphocytes and 10\% eosinophils) meeting all Light's criteria. Pleural fluid adenosine deaminase was low $\left(22 \mathrm{U} \cdot \mathrm{L}^{-1}\right)$ and smears, cultures and cytology were negative, while thoracoscopy failed due to markedly thickened pleura. Etanercept was discontinued and parenteral piperacillin/ tazobactam and ciprofloxacin and oral isoniazide, rifampin, ethambutol and pyrazinamide were started. Despite treatment, fever and the effusion persisted, resolving spontaneously after 40 days. The pleurisy relapsed, 20 days later, on the left side accompanied by a small pericardial effusion (fig. 1d, e and f). Thoracentesis revealed an exudate $(\mathrm{pH} 7.42$, glucose $111 \mathrm{mg} \cdot \mathrm{dL}^{-1}, \mathrm{LDH} 210 \mathrm{U} \cdot \mathrm{L}^{-1}$, protein $3.3 \mathrm{~g} \cdot \mathrm{dL}^{-1}, 2,600 \mathrm{cells} \cdot \mathrm{mm}^{-3}$, $80 \%$ lymphocytes, $20 \%$ neutrophils) with low adenosine deaminase $\left(21 \mathrm{U} \cdot \mathrm{L}^{-1}\right)$ and negative smears, cultures and cytology. Repeat serology was: RF $68 \mathrm{U} \cdot \mathrm{L}^{-1}$, ANA 1:1280, anti-dsDNA $9 \mathrm{U} \cdot \mathrm{L}^{-1}$, and anti-histone antibodies $3.7 \mathrm{U} \cdot \mathrm{L}^{-1}$. Pleural fluid complement was decreased (C3 28 and C4 $3.7 \mathrm{mg} \cdot \mathrm{dL}^{-1}$ ) to $30 \%$ of serum values (C3 88 and $\left.\mathrm{C} 414.4 \mathrm{mg} \cdot \mathrm{dL}^{-1}\right)$.

SLE-like syndrome was diagnosed based on fever, haemolytic anaemia, leukocytopaenia, microscopic haematuria, serositis and positive serology [8], and on ruling out alternative diagnoses. Isoniazide-induced effusion was deemed unlikely: the first effusion appeared without the patient taking the drug and the patient displayed systemic manifestations. The low $\mathrm{pH}$ and the eosinophils present in the first effusion have not been reported previously [7] and were ascribed to intense inflammation. A dose of $0.5 \mathrm{mg} \cdot \mathrm{kg}^{-1}$ oral prednisolone was installed, with prompt clinical and radiological resolution and the patient remained well after 16 months of follow-up.

We retrospectively examined the time-course of various markers in the patient's serum (fig. 1g-j). RF was determined by the RoseWaaler test, ANA by indirect immunofluorescence on rat kidney, TNF- $\alpha$ and IFN- $\alpha$ by ELISA (R\&D, Minneapolis, MN, USA). Equivocal changes in serum RF were coupled with peaking serum ANA during pleural effusion presentation. Unlike what is seen during health, serum TNF- $\alpha$ was detectable and was decreased after etanercept discontinuation, in accordance with observed elevations in serum TNF- $\alpha$ found in etanercept-treated cancer patients [9]. In addition, IFN- $\alpha$ was present in serum and in the second pleural effusion, an occurrence observed in patients with SLE-like syndrome but not in healthy subjects and patients with RA $[5,10]$.

Our findings support a pathogenesis of skewed autoimmunity rather than of a common drug reaction for the syndrome, as was elegantly elucidated in a recent study [5]. The authors witnessed uniform transcriptional activation of IFN- $\alpha$-regulated genes in patients with SLE and anti-TNF- $\alpha$-treated juvenile-onset RA but not in untreated patients with juvenileonset RA or in healthy volunteers. They further documented that TNF- $\alpha$, overexpressed in RA, exerted inhibitory effects on plasmatocytoid dendritic cell expansion and systemic release of IFN- $\alpha$, a culprit for SLE. These data were directly relevant with the occurrence of SLE-like syndrome, when TNF- $\alpha$ is targeted in patients with RA, and with the circulating and local pleural IFN- $\alpha$ identified in our patient with the syndrome.

Whatever the mechanism behind the systemic lupus erythematosus-like syndrome, respiratory specialists need to be aware of this occurrence, as the increasing use of biological disease modifiers in modern translational medicine is anticipated to yield unprecedented clinical encounters. 

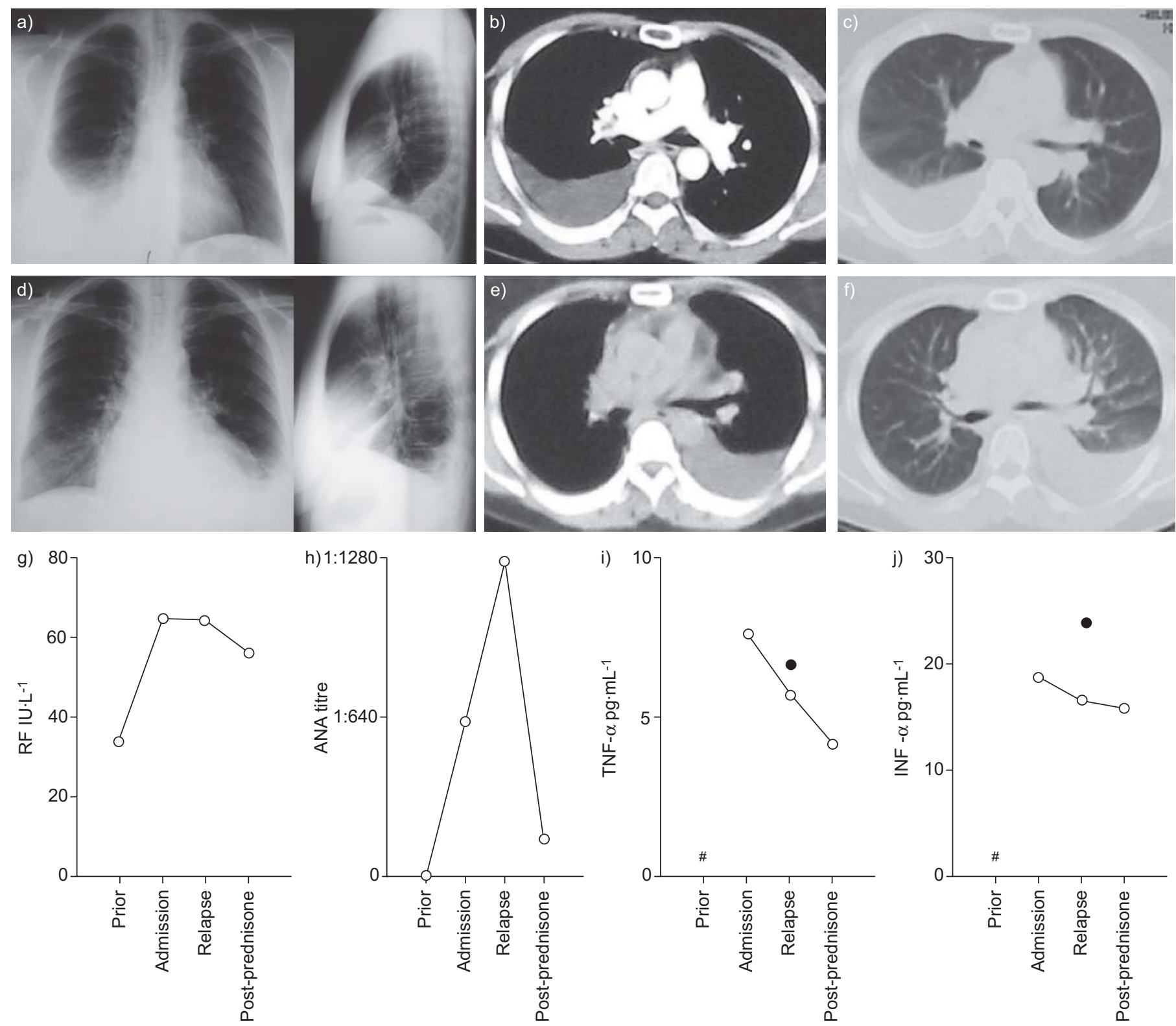

FIGURE 1. A 50-yr-old female with rheumatoid arthritis treated with etanercept presented with alternating pleural effusions as a manifestation of lupus-like syndrome a) Chest radiograph, b) soft tissue-gated chest computed tomography (CT) scan, and c) lung parenchymal gated chest CT scan during admission (day 0). d) Chest radiograph, e) soft tissue-gated chest CT scan, and f) lung parenchymal gated chest CT scan on day 60. g) Levels of rheumatoid factor (RF), h) antinuclear antibody (ANA), i) tumour necrosis factor (TNF)- $\alpha$ and j) interferon (IFN)- $\alpha$ in serum $(\bigcirc)$ and pleural fluid $(\bullet)$. The different time-points represent 1 yr prior to presentation (prior), at admission with right-sided pleural effusion (admission), at relapse with left-sided pleural effusion (relapse); and at one month post-prednisone installation (post-prednisone). ${ }^{*}$ : not available.

I. Porfyridis*, I. Kalomenidis", I. Psallidas\#, G. Stratakos*, C. Roussos*, T. Vassilakopoulos* and G.T. Stathopoulos* *Dept of Critical Care and Pulmonary Services, and ${ }^{\# 2 n d ~ D e p t ~}$ of Pulmonary Medicine, National and Kapodistrian University of Athens, Athens, Greece.

\section{SUPPORT STATEMENT}

This study was supported by the Thorax Foundation (Athens, Greece).

\section{STATEMENT OF INTEREST}

None declared.

\section{REFERENCES}

1 McDevitt H, Munson S, Ettinger R, Wu A. Multiple roles for tumor necrosis factor- $\alpha$ and lymphotoxin $\alpha / \beta$ in immunity and autoimmunity. Arthritis Res 2002; 4: Suppl. 3, S141-S152.

2 Elliott MJ, Maini RN, Feldmann M, et al. Randomized double-blind comparison of chimeric monoclonal antibody to tumor necrosis factor- $\alpha$ (cA2) versus placebo in rheumatoid arthritis. Lancet 1994; 344: 1105-1110.

3 Dixon WG, Symmons DP, Lunt M, et al. Serious infection following anti-tumor necrosis factor- $\alpha$ therapy in patients with rheumatoid arthritis: lessons from interpreting data 
from observational studies. Arthritis Rheum 2007; 56: 2896-2904.

4 Shakoor N, Michalska M, Harris CA, Block JA. Druginduced systemic lupus erythematosus associated with etanercept therapy. Lancet 2002; 359: 579-580.

5 Palucka AK, Blanck JP, Bennett L, Pascual V, Banchereau J. Cross-regulation of TNF and IFN- $\alpha$ in autoimmune diseases. Proc Natl Acad Sci USA 2005; 102: 3372-3377.

6 Bobbio-Pallavicini F, Alpini C, Caporali R, Avalle S, Bugatti S, Montecucco C. Autoantibody profile in rheumatoid arthritis during long-term infliximab treatment. Arthritis Res Ther 2004; 6: R264-R272.

7 Abunasser J, Forouhar FA, Metersky ML. Etanerceptinduced lupus erythematosus presenting as a unilateral pleural effusion. Chest 2008; 134: 850-863.
8 Hochberg MC. Updating the American College of Rheumatology revised criteria for the classification of systemic lupus erythematosus. Arthritis Rheum 1997; 40: 1725.

9 Madhusudan S, Foster M, Muthuramalingam SR, et al. A phase II study of etanercept (Enbrel), a tumor necrosis factor- $\alpha$ inhibitor in patients with metastatic breast cancer. Clin Cancer Res 2004; 10: 6528-6534.

$10 \mathrm{Abb} \mathrm{J}$, Kochen M, Deinhardt F. Interferon production in male homosexuals with the acquired immune deficiency syndrome (AIDS) or generalized lymphadenopathy. Infection 1984; 12: 240-242.

\section{No lung cancer at resection of PET positive lesions: an audit of the lung cancer multidisciplinary team}

\section{To the Editors:}

An essential role of the lung cancer multidisciplinary team (MDT) is to provide an accurate and prompt diagnosis enabling resection of malignant disease where appropriate, while minimising the risk of unnecessary surgical intervention. Since $2005,{ }^{18}$ F-deoxy-D-glucose positron emission tomography -computed tomography $\left({ }^{18}\right.$ FDG PET-CT) has been recommended for all patients with potentially radically treatable disease as part of the routine lung cancer staging process [1]. The Leeds Teaching Hospital (Leeds, UK) lung cancer MDT is a regional centre with an approximate workload of 500 patients with lung cancer per year. Within the lung cancer MDT, concern was raised regarding a series of patients referred for surgical resection who had a nonmalignant diagnosis at lung resection. It was decided to audit patients referred for surgical resection to determine the frequency of a benign diagnosis at resection. Standard practice within the lung cancer MDT is for patients to undergo thorough clinical assessment, followed by a contrast-enhanced CT scan of the chest and upper abdomen. ${ }^{18}$ FDG PET-CT scanning is selectively used if the patient may be suitable for potentially curative treatment. Depending upon the size and location of the suspected lung tumour, a tissue diagnosis is attempted via either fibreoptic bronchoscopy or CT-guided percutaneous needle biopsy.

All patients with a solitary pulmonary nodule presented at the lung cancer MDT were identified retrospectively from the lung cancer database between August 1, 2005, and August 30, 2008. The case records of the subset of patients who were referred for surgical resection were reviewed, and data pertaining to the investigations undertaken during the lung cancer diagnostic pathway and the final histological diagnosis at lung resection were obtained.

During the study period, 145 patients were referred for surgical resection. Of the patients, $52 \%$ were male and $48 \%$ were female. The median age of the patients was $69.5 \mathrm{yrs}$ (range 41.4-88.8 yrs). The most common diagnosis at resection was nonsmall cell carcinoma (table 1). Of the patients, $78(54 \%)$ had a solitary pulmonary nodule in which a tissue diagnosis could not be established prior to referral for surgical resection. All of these patients had received a thorough clinical assessment, and CT and ${ }^{18}$ FDG PET-CT scans. The opinion of the lung cancer MDT regarding these patients was that there was there was a high suspicion of a lung cancer based upon clinical and radiological assessment and, as a tissue diagnosis was not technically possible, surgical referral for resection was felt to be the appropriate course of action. Of the patients without a tissue diagnosis prior to surgical referral, $7.69 \%$

\section{TABLE 1 Diagnosis at surgical resection}

\begin{tabular}{lc} 
Diagnosis at surgical resection & Subjects \\
\hline Primary lung adenocarcinoma & $61(42)$ \\
Squamous carcinoma & $52(36)$ \\
Large cell carcinoma & $13(9)$ \\
Adenosquamous carcinoma & $3(2)$ \\
Large cell neuroendocrine tumour & $3(2)$ \\
Carcinoid tumour & $2(1.4)$ \\
Small and large cell carcinoma & $2(1.4)$ \\
Aspiration pneumonia & $1(0.7)$ \\
Chronic inflammation & $1(0.7)$ \\
Metastatic malignant melanoma & $1(0.7)$ \\
Metastatic colon carcinoma & $1(0.7)$ \\
Nonspecific inflammation & $1(0.7)$ \\
Pulmonary infarct secondary to Churg-Strauss & $1(0.7)$ \\
Small cell carcinoma & $1(0.7)$ \\
Tuberculoma & $1(0.7)$ \\
Abscess and organising pneumonia & $1(0.7)$
\end{tabular}

